\title{
Penetrating chest trauma secondary to a composite hockey stick injury
}

\author{
Joel Kennedy, BScH; ${ }^{*}$ Robert S. Green, BSc, MD; $;{ }^{\dagger \dagger}$ Harry Henteleff, $\mathrm{MD}^{\S}$
}

\begin{abstract}
Hockey is enjoyed by millions of people around the world and is a sport in which aggression is encouraged and injuries are common. Although body-checking is the most common cause of injury in hockey today, hockey sticks are associated with up to $14 \%$ of injuries. We report a case of chest trauma requiring surgical intervention secondary to the penetration of a composite hockey stick into a player's thoracic cavity.
\end{abstract}

Key words: ice hockey; composite hockey stick; chest trauma; penetrating injury

RÉSUMÉ

Des millions de personnes partout dans le monde sont des amateurs de hockey, un sport où l'agressivité est encouragée et où les blessures sont fréquentes. Bien que la mise en échec soit la cause la plus courante de blessures au hockey de nos jours, les bâtons de hockey sont pour leur part responsables de $14 \%$ des blessures. Nous présentons un cas de blessure au thorax ayant nécessité une intervention chirurgicale à la suite de la pénétration d'un bâton de hockey en matériau composite dans la cavité thoracique d'un joueur.

\section{Introduction}

Ice hockey is considered one of the fastest and most aggressive team sports. ${ }^{1}$ Defined as a game played with clubs (hockey sticks), knives (skates) and bullets (pucks), ${ }^{2-4}$ its violence parallels that seen daily within emergency medicine. Despite this, ice hockey is enjoyed by millions of people worldwide and is attracting an increasing number of participants not only in Canada, but internationally.

Hockey-related injuries are common, with one report of more than 30000 presentations to US emergency departments (EDs) in 2001. ${ }^{3}$ The annual incidence of spinal cord injury with paralysis as a result of an injury acquired while playing hockey in Canada is 3 times greater than that re- ported for American football. ${ }^{5}$ The majority of injuries are secondary to blunt trauma and are minor in nature; however, accounts of significant morbidity and mortality have been published. ${ }^{5,6}$ Although not commonly reported, hockey sticks can cause significant harm and may account for up to $14 \%$ of hockey-related injuries. ${ }^{1,7,8}$

We report a case of penetrating chest trauma requiring surgical intervention after a player's broken composite hockey stick impaled a teammate's thoracic cavity.

\section{Case report}

A 23-year-old man presented to a community ED 25 minutes after colliding with a teammate while attempting to

*Medical student, 3rd year, Dalhousie University, Halifax, NS

tDepartment of Emergency Medicine, Queen Elizabeth II Health Sciences Centre, Dalhousie University, Halifax, NS

‡Department of Internal Medicine, Division of Critical Care Medicine, QEII Health Sciences Centre, Dalhousie University, Halifax, NS

§Department of Surgery, Division of Thoracic Surgery, QEII Health Sciences Centre, Dalhousie University, Halifax, NS

Received: June 23, 2006; revisions received: Sept. 6, 2006; accepted: Sept. 23, 2006

This article has been peer reviewed.

Can J Emerg Med 2006;8(6):437-40 
bodycheck an opposing player during a Canadian Interuniversity Sport hockey game. Upon collision, the teammate's stick fractured and pierced the player's chest wall (Fig. 1 and Fig. 2). The stick must have entered and then exited the player's chest wall immediately, as it was not until after skating away from the collision that the teammate noticed that his stick was fractured. The injured patient skated to the bench without assistance, where the team trainer discovered a laceration to the patient's left axilla, and arranged transport to the ED.

On arrival at the ED, the patient complained of $6 / 10$ pain on deep inspiration in the mid-sternal and upper back regions. Initial vital signs included a blood pressure of 132/72 $\mathrm{mm} \mathrm{Hg}$, heart rate of 93 beats/min, respiratory rate of 20 beats $/ \mathrm{min}$, room air oxygen saturation of $98 \%$, and temperature $37.7^{\circ} \mathrm{C}$. The patient was alert, oriented and communicating appropriately. Examination of the thorax revealed a 5-cm laceration in the left axilla just posterior to the anterior axillary line, with exposed muscle. Breath sounds were normal, but chest radiography revealed a left-sided pneumothorax. Under sterile conditions and with the aid of local anesthesia, a \#28 French chest tube was placed after phone consultation with a thoracic surgeon. The patient was referred to a tertiary care ED for further assessment and was transferred without incident.

A repeat chest $\mathrm{x}$-ray performed after transfer suggested pneumomediastinum, but vital signs were unchanged. The chest wall wound was débrided and closed at the bedside, and the chest tube was connected to suction. The patient was admitted to hospital for monitoring.

A computed tomography (CT) scan the following day revealed a hemopneumomediastinum (Fig. 3). Clinically the patient appeared well, and his vital signs were stable.

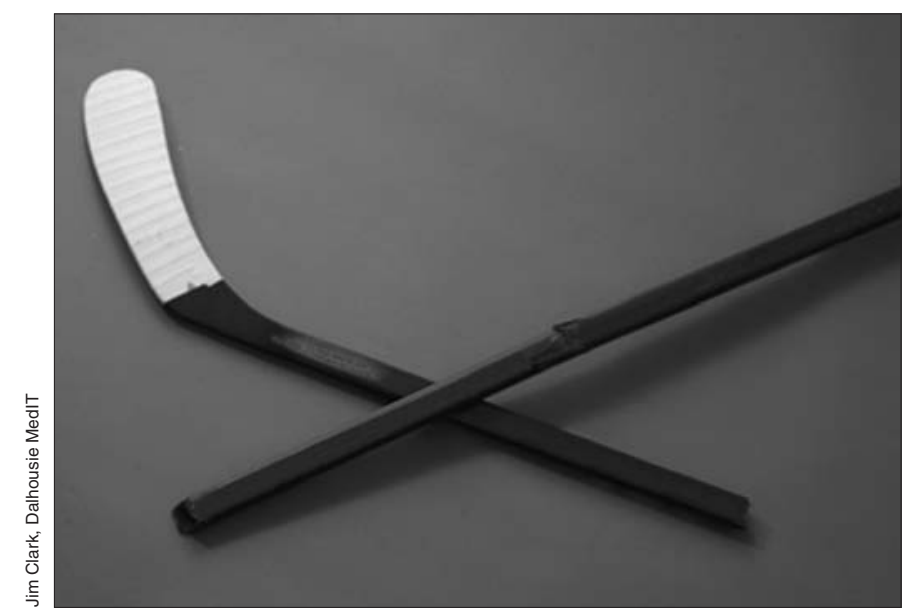

Fig. 1. Composite hockey stick that penetrated left axilla of patient. Stick is fractured in 2 places, rendering 3 fragments.
However, on day 3 post-admission he was found to have ongoing wound drainage (250-325 mL/day), persistent pneumothorax and pneumomediastinum, and a reduction of oxygen saturation to $90 \%$ on room air. The hypoxemia coincided with a slight rise in temperature and resolved when his temperature normalized. He was taken to the operating room, where the wound was reopened, débrided and left open to heal, with a Penrose drain left in situ. The patient tolerated the procedure well.

His immediate postoperative course was complicated by a persistent pneumothorax, pleural effusions, hypoxemia $\left(\mathrm{O}_{2}\right.$ saturation of $88 \%-90 \%$ room air $)$, and ongoing drainage from the chest wall laceration. The oxygen saturation improved within 24 hours, and the pneumothorax and pleural effusions resolved over the next 2 days. On day 6 the patient was found to be febrile $\left(38.5^{\circ} \mathrm{C}\right)$, and tachycardic (120 beats/min); oral antibiotics were initiated for a presumed wound infection. The patient improved over the next 4 days and was discharged home after 9 days in hospital. He has since fully recovered and returned to competitive ice hockey.

\section{Discussion}

Ice hockey competition often results in traumatic injury, which has been correlated with player age, size and level of competition. ${ }^{3,9-11}$ As players mature, the level of competition becomes faster and increasingly violent. Multiple studies implicate bodychecking as a major risk factor for injury, ${ }^{12,13}$ and half of all competitive hockey injuries are due to collisions. ${ }^{7}$ Of interest, Hockey Canada has recently reduced the age limit for bodychecking from 12-13 years to 9 years of age. ${ }^{12}$

Advances in technology have improved equipment, but not necessarily reduced injury. Although facial lacerations and contusions have been reduced through the use of helmet and facemask protection, spinal injuries have increased to 15 cases per year in Canada, and concussions to approximately $18.6 \%$ of all injuries. ${ }^{1,3,5,6}$ In addi-

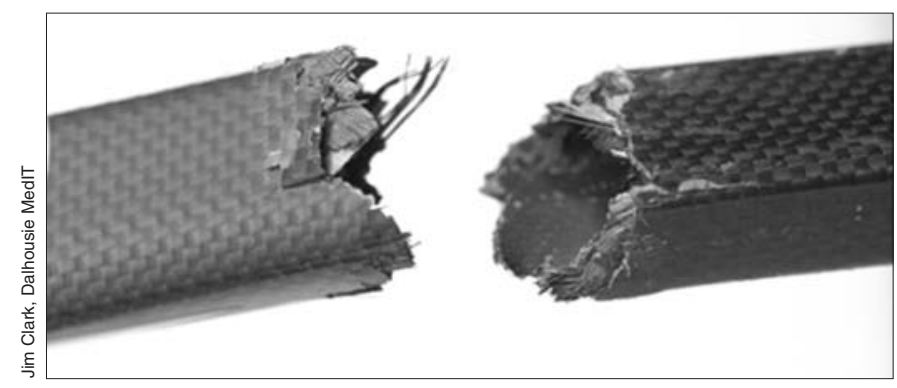

Fig. 2. Close-up of broken hockey stick, showing jagged edges. 
tion, the number of traumatic brain injuries has increased. ${ }^{3,5}$ An estimated 17000 head injuries and approximately 4800 concussions occurred in the US from 1993-1999 as a result of ice hockey. ${ }^{14}$ A comparison of players in the Finnish Elite League from the 1970s through the 1990s demonstrated a 3-fold increase of sprains and strains. In addition, the investigators found that the overall game injury risk in the 1990s was 1.52 times greater than that reported in the 1970s. ${ }^{9}$ The upper extremity is the most common injury location..$^{1-3,9}$ This is especially prevalent in minor hockey, where the Canadian Hospitals Injury Reporting and Prevention Program (CHIRPP) indicated that $46.6 \%$ of injuries were of the upper extremity ${ }^{2}$ and approximately half of these were fractures. In the 4 age groups (Atom, Pee Wee, Bantam and Midget) analyzed by CHIRPP, ${ }^{2}$ the clavicle was the most frequent fracture, at $33 \%$.

Hockey sticks have been implicated in up to $14 \%$ of injuries and are most commonly associated with contusions, lacerations and fractures. ${ }^{1,7,8}$ Molsa and colleagues ${ }^{9}$ reported a growing injury rate relating to hockey sticks in the 1990s. A 2003 study $^{15}$ reported that $19 \%$ of distal extremity injuries were a direct result of a blow with a stick, and $4 \%$ of those were fractures. Facial trauma accounts for $11.5 \%$ of hockey-related injuries in Finland, and Lahti and colleagues estimated that hockey sticks were involved in 54\% of facial trauma. ${ }^{16}$ In the 1970 s Pashby ${ }^{17}$ conducted a survey of Canadian Ophthalmological Society members on eye injuries in hockey and con-

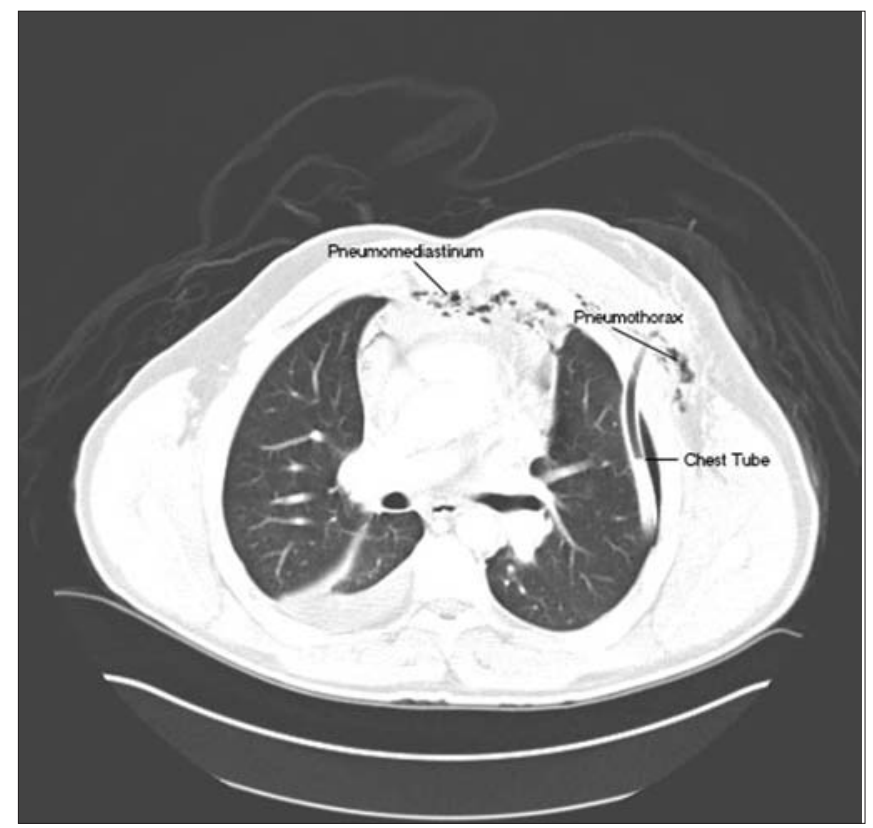

Fig. 3. CT scan demonstrating a left pneumothorax and pneumomediastinum. cluded that a majority of injuries were caused by hockey sticks, and that $13.7 \%$ of injured players became legally blind. ${ }^{17}$

Penetrating injuries are uncommon in ice hockey and consequently are not widely reported. One case involved penetrating chest trauma secondary to a skate blade resulting in near complete transection of the axillary artery and hypotensive shock..$^{18}$ A literature review of PubMed and Web of Science databases using keywords "penetrating injury," "hockey stick," "ice hockey injury," "hockey trauma" and "stick laceration" revealed no other cases of penetrating trauma.

Traditionally, hockey sticks have been constructed with a wood and glue base. To improve performance and durability, composite materials such as fibreglass, carbon graphite and aluminum, among other products, have been added. In the 1990s, composite hockey sticks gained popularity with both competitive and non-competitive players. Unlike wooden sticks, composites can be made in one piece or in two pieces, with the difference being weight, flexibility and blade fusion with the shaft. Although these new composite sticks are purported to improve shooting, a recent study by $\mathrm{Wu}$ and colleagues ${ }^{19}$ concluded that there is minimal improvement in shot velocity in composite sticks when compared with traditional wooden sticks. However, composite sticks are thought to be lighter and more rigid, which unfortunately may result in stick fracture with sharp, penetrable fragments. It is possible that fractured composite sticks may more easily allow penetrating trauma, as seen in our case.

Our case is unique for 2 reasons: first, penetrating chest trauma occurred during a hockey game, and second, the hockey stick was a composite. Due to the speed and aggressive nature of competitive hockey, penetrating chest trauma is possible from various objects. However, the fact that similar injuries have not been previously reported, combined with the fracture of the composite hockey stick in this case is interesting.

We have found no available standards for manufacturers of hockey sticks (wooden, composite or otherwise) to guard against potentially unsafe equipment. Moreover, many players at all levels play with modified or substandard equipment. With the increasing number of players and subsequent injuries, safety standards may require more emphasis and improved enforcement. Additionally, a mechanism for monitoring hockey injuries could lead to identification of potential improvements in equipment design. Manufacturers of sports equipment should be encouraged to target modifications that also reduce known injuries. 


\section{Conclusion}

Improvements and changes in hockey and other sports equipment have the potential to introduce new patterns of injury, as illustrated by a case of penetrating chest injury from a composite hockey stick. Further study is warranted to determine whether composite hockey sticks are associated with an increase in injury rates.

Acknowledgement: We thank Mr. Jim Clark, Dalhousie University, for supplying photographic support.

Competing interests: None declared.

\section{References}

1. Flik K, Lyman S, Marx RG. American collegiate men's ice hockey: an analysis of injuries. Am J Sports Med 2005;33:183-7.

2. McFaull S. Contact injuries in minor hockey: a review of the CHIRPP database for the 1998/1999 hockey season. Canadian Hospitals Injury Reporting and Prevention Program (CHIRPP) News - Canada Public Health Agency. 2001.

3. Hostetler SG, Xiang H, Smith GA. Characteristics of ice hockey-related injuries treated in US emergency departments, 2001-2002. Pediatrics 2004;114:e661-6.

4. Sim FH, Chao EY. Injury potential in modern ice hockey. Am J Sports Med 1978;6:378-84.

5. Banerjee R, Palumbo MA, Fadale PD. Catastrophic cervical spine injuries in the collision sport athlete, part 1: Epidemiology, functional anatomy, and diagnosis. Am J Sports Med 2004; 32:1077-87.

6. Molsa JJ, Tegner Y, Alaranta H, et al. Spinal cord injuries in ice hockey in Finland and Sweden from 1980 to 1996. Int J Sports Med 1999;20:64-7.

7. Stuart MJ, Smith A. Injuries in junior A ice hockey. A threeyear prospective study. Am J Sports Med 1995;23:458-61.

8. Lorentzon R, Wedren H, Pietila T. Incidence, nature, and causes of ice hockey injuries. A three-year prospective study of a swedish elite ice hockey team. Am J Sports Med 1988;16:392-6.

9. Molsa J, Kujala U, Nasman O, et al. Injury profile in ice hockey from the 1970s through the 1990s in Finland. Am J Sports Med 2000;28:322-7.

10. Rielly MF. The nature and causes of hockey imjuries: A fiveyear study. Athl Train 1982;17:88-90.

11. Daffner RH. Injuries in amateur ice hockey: a two-year analysis. J Fam Pract 1977;4:225-7.

12. Marchie A, Cusimano MD. Bodychecking and concussions in ice hockey: Should our youth pay the price? CMAJ 2003; 169:124-8

13. Canadian Academy of Sport Medicine Sport Safety Committee. Violence and injuries in ice hockey [position statement]. The Academy. 1988.

14. Delaney JS. Head injuries presenting to emergency departments in the United States from 1990 to 1999 for ice hockey, soccer, and football. Clin J Sport Med 2004;14:80-7.

15. Molsa J, Kujala U, Myllynen P, et al. Injuries to the upper extremity in ice hockey: analysis of a series of 760 injuries. Am J Sports Med 2003;31:751-7.

16. Lahti H, Sane J, Ylipaavalniemi P. Dental injuries in ice hockey games and training. Med Sci Sports Exerc 2002;34:400-2.

17. Pashby TJ. Eye injuries in canadian amateur hockey. Am J Sports Med 1979;7:254-7.

18. Barter R. Two unusual penetrating injuries from playing ice hockey. CMAJ 1999;161:1535-6.

19. Wu T-C, Pearsall D, Hodges A, et al. The performance of the ice hockey slap and wrist shots: the effects of stick construction and player skill. Int Sports Engineering Assoc 2003;6:31-40.

Correspondence to: Dr. Rob Green, Assistant Professor, Department of Emergency Medicine, Dalhousie University, Rm. 377, Bethune Building, 1278 Tower Rd., Halifax NS B3H 2 Y9 